\title{
Endoscopic fundoplication in a pediatric patient: a new concept
}

Endoscopic transoral incisionless fundoplication (TIF) has been shown to be efficacious and safe in the management of gastroesophageal reflux disease (GERD) [1-3], including in patients with GERD who have undergone peroral endoscopic myotomy (POEM) for achalasia [4]. However, the safety of TIF in the pediatric population is unknown. This video case report is the first to evaluate the role of TIF for the management of GERD in a pediatric patient.

A 13-year old patient developed symptomatic reflux after undergoing POEM. Because of the potential side effects of long-term proton-pump inhibitor (PPI) use, the patient opted to undergo TIF ( Video 1). The Esophyx Z device (Endogastric Solutions, Redmond, Washington, USA) was passed over a flexible endoscope (GIF-190; Olympus) into the stomach. The plastic jaw was closed, and a retroflexed view of the device confirmed it was in the knuckle position. The plastic jaw was positioned at the lip of the gastroesophageal junction at the 11-o'clock position. The helical retractor was advanced, and the gastric tissue was coiled, retracted, and rotated counterclockwise to create the wrap ( $\triangleright$ Fig.1). After the plastic jaw was locked, an invaginator was activated. Polypropylene fasteners were deployed through the retracted tissue. Once the tissue was secure, the invaginator was inactivated and the wrapped tissue was released. The procedure was repeated at the 1-o'clock, 5-o'clock, and 7-o'clock positions, forming a 270-degree fundoplication. After the wrap had been created, a flexible endoscope was used to examine the fundoplication ( $\triangleright$ Fig.2). A total of 20 fasteners were deployed in the procedure. Post-procedure, the patient was admitted for a single night's observation. At 6 months after the procedure, the patient remains asymptomatic and does not require PPI medications.

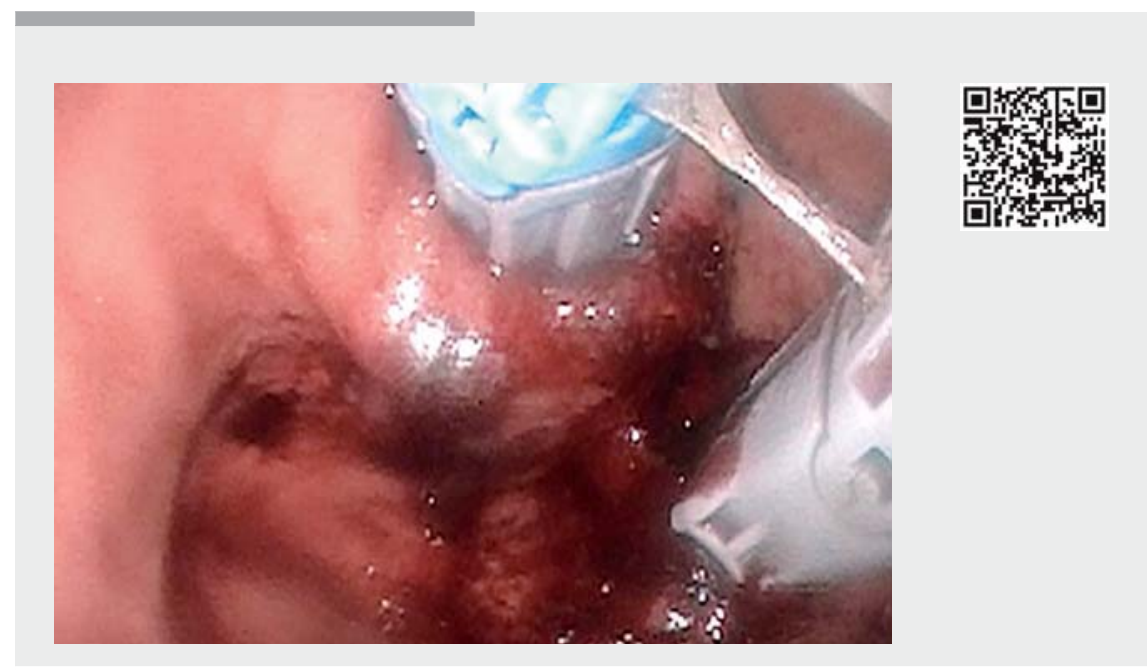

Video 1 Endoscopic transoral incisionless fundoplication in a pediatric patient.

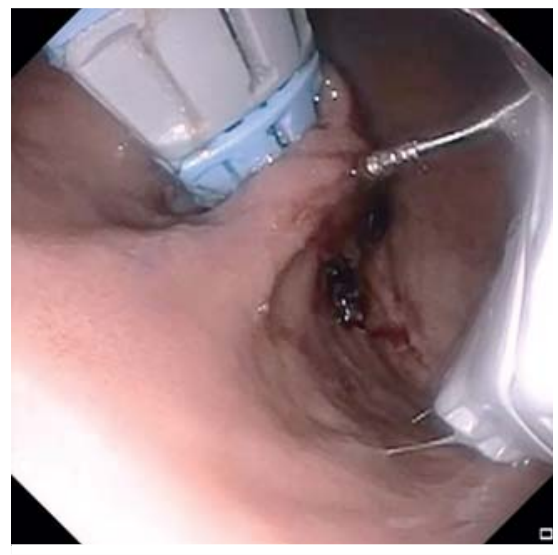

- Fig. 1 Transoral incisionless fundoplication in a 13-year-old patient: gastric tissue being retracted with the helical retractor.

TIF is an efficacious and safe intervention in the treatment of GERD. This is the first case of a successful TIF procedure being conducted in a pediatric patient, suggesting the feasibility of TIF in pediatric patients.

Endoscopy_UCTN_Code_TTT_1AO_2AJ

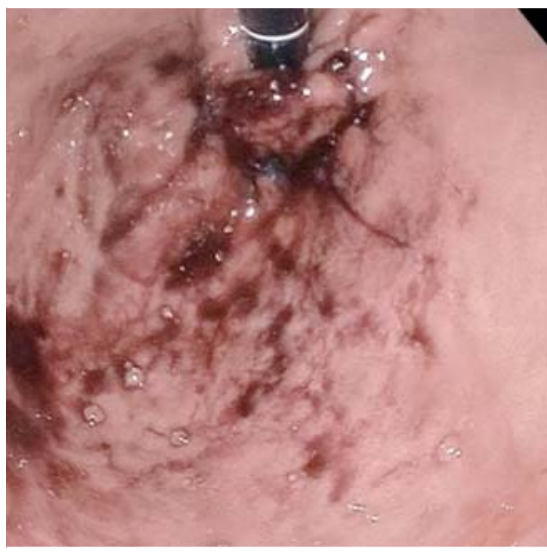

- Fig. 2 Final endoscopic image of the completed fundoplication.

Competing interests

M. Kahaleh has received grant support from Boston Scientific, Fujinon, EMcison, Xlumena, W.L. Gore, MaunaKea, Apollo Endosurgery, Cook Endoscopy, ASPIRE Bariatrics, GI Dynamics, NinePoint Medical, Merit Medical, Olympus, and MI Tech; he is a consultant for Boston Scientific, Xlumena, Concordia Laboratories, ABBvie, and MaunaKea Tech. A. Tyberg is a consultant for Boston Scientific, EndoGastric Solutions, and NinePoint Medical. 
The authors

Amy Tyberg' ${ }^{1}$, Kopal Jha², Monica Gaidhane ${ }^{1}$, Michel Kahaleh ${ }^{1}$

1 Rutgers University, Robert Wood Johnson Medical School, New Jersey, USA

2 Cornell University, Ithica, New York, USA

Corresponding author

\section{Michel Kahaleh, MD}

Rutgers, The State University of New Jersey, Robert Wood Johnson University Hospital,

1 RWJ Place, MEB 464, New Brunswick, N) 08901, USA

Fax: +1-732-235-5537

mkahaleh@gmail.com

\section{References}

[1] Trad KS, Barnes WE, Simoni G et al. Transoral incisionless fundoplication effective in eliminating GERD symptoms in partial responders to proton pump inhibitor therapy at 6 months: the TEMPO Randomized Clinical Trial. Surg Innov 2015; 22: $26-40$

[2] Hunter JG, Kahrilas PJ, Bell RC et al. Efficacy of transoral fundoplication vs omeprazole for treatment of regurgitation in a randomized controlled trial. Gastroenterology 2015; 148: 324-333.e5. Epub 2014 Oct 13

[3] Trad KS, Simoni G, Barnes WE et al. Efficacy of transoral fundoplication for treatment of chronic gastroesophageal reflux disease incompletely controlled with high-dose proton-pump inhibitors therapy: a randomized, multicenter, open label, crossover study. BMC Gastroenterol 2014; 14: 174

[4] Tyberg A, Choi A, Gaidhane M et al. Transoral incisionless fundoplication for reflux after peroral endoscopic myotomy: a crucial addition to our arsenal. Endosc Int Open 2018; 6: E549-E552

\section{Bibliography}

DOI https://doi.org/10.1055/a-0889-7199

Published online: 7.6.2019

Endoscopy 2019; 51: E343-E344

(c) Georg Thieme Verlag KG

Stuttgart · New York

ISSN 0013-726X

\section{ENDOSCOPY E-VIDEOS}

https://eref.thieme.de/e-videos

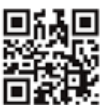

Endoscopy E-Videos is a free access online section, reporting on interesting cases and new

techniques in gastroenterological endoscopy. All papers include a high quality video and all contributions are freely accessible online.

This section has its own submission website at

https://mc.manuscriptcentral.com/e-videos 